\title{
PROBLEMS IN COMMUNICATING INFORMATION
}

$\mathrm{A}^{\mathrm{T}}$

$T$ the present time, when communication is being examined from many theoretical points of view, an empirical discussion grounded in research seemed desirable, and the Northern Branch of the British Psychological Society, meeting at the University of Leeds on February 12, provided a suitable forum. Of the five participants, all had a practical interest in communication, and between them they represented its literary, scientific, industrial and psychological aspects. All are actively engaged in research in one or other aspects of communication. The discussion never soared philosophically but was focused mainly upon the problem of transmitting scientific data and concepts, with particular emphasis upon the industrial 'consumers' of science.

The symposium provided an occasion for reviewing the preliminary findings in a piece of research on "the comprehensibility of technical reports" undertaken six months ago by the Department of Psychology, University of Leeds, with a grant from the Department of Scientific and Industrial Research. It should be made clear that these 'findings' are no more than first impressions concerning the nature of the problem itself-namely, the problem of easing and increasing the flow of information from the laboratory to the factory, a problem with an obvious bearing upon industrial productivity. All those who are familiar with the facts of the matter will appreciate the difficulty in finding any clear track through the maze of diverse practices, materials, documents and human attitudes in this field. The discussion, here summarized, was intended primarily to indicate methods of approach. Its scope is indicated by the programme: the comprehension of technical literature in the factory (Miss Frances Crisp, Department of Psychology, Leeds) ; experimental studies of scientific vocabulary in relation to comprehension (Dr. W. E. Flood, Department of Education, Birmingham); problems of research in reading and comprehension (Miss M. E. Meek, Institute of Education, Leeds) and some methodological problems concerning the flow of information (Dr. R. Harper and Prof. G. P. Meredith, Department of Psychology, Leeds).

Miss Crisp confined her remarks to conditions in the wool textile industry, where for obvious geographical reasons she has done her preliminary fieldwork. 'This is not a 'typical' industry; but what industry is typical? It is an industry in which historical factors play a still dominant part, not only in the industry as a whole but also in individual works, a history of persistent competitiveness in which the need for a "flow of information' is crisscrossed by habits of mutual secrecy concerning specialized bits of 'know-how'. Her inquiries concerming the flow of literature showed that, while there is much wastage through indiscriminate distribution, clearly illustrated material has a way of attracting attention, sometimes unexpectedly and with beneficial results. Advertising can be a valuable vehicle of information, although the reluctance of many British advertisers to state prices is a hindrance. With scientific journals the time-lag in publication is a serious brake upon the rapid transmission of information. An even more serious obstacle is the style in which many scientific papers are written. Industrial readers frequently find them unduly ponderous, and would show greater interest in research if they understood more of what was written. The need for someone to play an interpretative part between the scientist and the industrial reader was a point taken up later in the symposium.

Dr. Flood's contribution, while not specifically concerned with industrial readers but rather with the popularization of science, directed attention to a technique which may well have something to offer to the problem of reducing the difficulty of scientific communication to industry. His paper referred to a number of investigations on popular reading matter and scientific broadcasts in which vocabulary was revealed as a decisive factor in comprehensibility. $\mathrm{He}$ described the method by which he and Michael West compiled their two-thousand word vocabulary, with the aid of which they were enabled to construct a dictionary of scientific terms. (One may comment here that this principle of "communication by vocabulary-control' can be appreciated only if its restriction to popular communication is borne in mind; it is clearly out of place in communication between experts.) A variety of examples illustrated the process of translation, of which a brief extract must here suffice : Original : "The foliage is usually persistent. The leaves are linear, linear-lanceolate, acicular or squamiform and have simple venation. The leaf-surface is often glabrous or lustrous". Translation in Flood-West vocabulary : "The leaves usually last for several years. They are straight and narrow, thin spear-shaped, needle-shaped or scalelike and the veins are simply arranged. The surface of the leaf is often smooth or shiny".

Dr. Flood also dealt with the understanding of concepts in so far as these have an inherent difficulty independent of vocabulary, and this was a matter further explored in the next paper, by Miss Margaret Meek. Here the symposium swung over to the reader's end of the communication process. While there are obvious problems in the very varying degree of actual reading skill (witness the spread of 'reading clinics' in the United States and the recent interest aroused in Great Britain), Miss Meek made it plain that comprehension, the final yield of the reading-process, demands something more than reading-skill in the current sense, and something more than a grasp of vocabulary. "As words do not have a one-to-one relationship with facts, but are dependent for their meaning not only on the context in which they occur but also on the associations they have for the reader . . 'word-meanings' offer both an excellent way and a wholly wrong way of discovering what the reader has understood of a passage. .. Comprehension is a cumulative process, a blending of the old information with the new". Miss Meek referred to the role of clues, allusions, metaphors and archaic meanings. She stressed the importance of motivation, attitude and preconception. She criticized the atomicity and frequent irrelevance of much of the testing of comprehension. (One might here recommend examiners to pay heed.) She urged the need to penetrate successive levels of comprehension by techniques which permit the reader to show in his own terms what a passage has meant for him. Here the psychological fact that reading is not an isolated cognitive activity, but an 
engagement of imagination and personality itself, emerged as the considered outcome of Miss Meek's researches.

Dr. Harper gave a broad survey of the "flow of information' regarded as a scientific problem, with the view of establishing the significant variables in the process. $\mathrm{He}$ characterized our present knowledge in this field as no more than a "natural history stage". $\mathrm{He}$ used the term "information" not in the current but still esoteric cybernetic sense, but simply as a "composite of facts, ideas, knowledge and techniques". Dr. Harper divided the field up into (1) media and methods; (2) material or message ; and (3) focal points. Under (1) he listed as four major points of inquiry : use of language; size and type of groups use of visual aids; and the scope for interaction and 'feed-back'. The B.B.C. concept of the 'target audience' is relevant here, under the heading of size and type of groups. He indicated the need for much greater specificity of aim if communication is to be effective. This applies equally to (2), that is, content of message. Under (3) he developed an interesting series of parallels between human and electronic communication while stressing the radical differences in the nature of the processes themselves; and he reminded would-be communicators of the axiom of "training within industry" that "if the worker has not learned, the teacher has not taught". He also emphasized Miss Meek's theme of the over-riding importance of attitudes and human motivation.

Prof. Meredith, in his concluding contribution to the symposium, stressed the differences rather than the parallels between human communication and communication-engineering. Basically our problem concerns a relation between the man in the laboratory and the man in the factory, differing in outlook, training and mode of life, yet mutually dependent. The scientific document is a slender and inadequate link between them. The man of science, if intent on his research, cannot usually make himself expert in communication techniques. The industrial expert has reasons, some good, some bad, for resisting knowledge which may change his practice. The advance of science must be matched by a corre. sponding advance in methods of communication. Improved communication demands not less but_more stress on human factors. Effective communication of the basic knowledge factors-materials, properties, processes, laws, concepts, historical bases and operational prescriptions - demands at its fullest a "sixpronged invasion force' of verbal, diagrammatic, pictorial, filmic, material and human carriers, under the command of an appropriately trained 'communications officer'.

G. P. Meredith

\section{HEALTH OF SCHOOL CHILDREN}

$\mathrm{P}$ ARENTS and others interested in the welfare of children will find, in the report of the Chief Medical Officer of the Ministry of Education for the years 1952 and 1953 (H.M.S.O., 1954; 5s. net), much that will interest and please them. Everywhere, the report assures us, the health of the children is satisfactory. In 1953 only $2 \cdot 2$ per cent of the children were considered by school doctors to be in poor general condition. Thanks to immunization, diphtheria is now a rare disease, and let us hope that everyone concerned, parents included, will co-operate to maintain this protection from a dreadful disease. Rickets scarcely exists, and if tetanus (lockjaw) could be also banished by similar measures, so much the better. Among children aged 5-14 suffering acute infectious diseases, about 90 per cent suffered from measles, whooping cough and scarlet fever. There has been, in recent years, a remarkable decrease in the number of deaths among children aged 5-14 from tuberculosis. In 1938 the number of children of this age-group who died of this disease was 973 , whereas in 1952 it was 168 , and in 1953, 107. In general, the incidence of acute rheumatism has also fallen sharply during the past ten years; but there have been exceptions in certain areas, and several principal school medical officers have reported an increase, in 1952 and 1953, of the number of children with rheumatic heart disease. There were still more than a quarter of a million children with nits and lice; but the number of verminous children was, nevertheless, the smallest. known in the history of the school medical service. Among the other subjects discussed by the report are food poisoning in schools, middleear disease and that puzzling bugbear of the parent, poliomyelitis.

Less reassuring is the section dealing with dental caries, which has increased, and there is strong evidence that sweet and sticky articles of diet are important causes of decay of teeth. The consumption of sugar per head of the population rose in 1946 (immediately after the War) and has continued at a higher level. It is suggested that reduction of sweet and sticky foods would reduce dental caries considerably.

The report strongly urges the retention, wherever this is possible, of handicapped children in the ordinary schools. Most of them have to go to work when they leave school and their school life should not be too sheltered. It is expected that early auditory training and the teaching of lip-reading will enable more children with defective hearing to attend ordinary schools in the future. Children with defective sight are already attending these schools more and more, and those with defective speech can be trained in them. Very severely handicapped children should not, however, be educated at the expense of other children, nor should teachers be asked to bear responsibilities in this respect that may be too exacting. For handicapped children, 222 new special schools have been opened since 1945, and these accommodate 14,165 handicapped children. Among them are 30 hospital special schools, in which about 8,000 children are being taught. An innovation in 1953 was the establishment, by the Diabetic Association, of three camps for diabetic children, in which these children can have a holiday with special care and diet. The British Epilepsy Association made a similar arrangement for epileptic children. An interesting chapter of the report discusses the baffling problem of asthma, on which much research is being done. A limited number of asthmatic children have been sent abroad for treatment; but medical opinion is divided about the wisdom of this procedure.

The introduction of the National Health Service has not had any serious effect on the School Health Service; but its provision of 'free' service by a general practitioner may have helped to reduce the number of children who attend clinics for minor ailments. School doctors in general have reported better co-operation between the general practitioners and themselves than ever before. 